\title{
MERCADO DE CADEIAS CURTAS NA PECUÁRIA FAMILIAR: UM PROCESSO DE RELOCALIZAÇÃO NO TERRITÓRIO ALTO CAMAQUÃ NO SUL DO RIO GRANDE DO SUL/BRASIL
}

\author{
MARKET SHORT CHAINS IN THE FAMILY LIVESTOCK: ONE \\ RELOCATION PROCESS IN THE TERRITORY ALTO \\ CAMAQUÃ IN SOUTHERN RIO GRANDE DO SUL/BRAZIL
}

\author{
Alessandra Matte \\ Universidade Federal do Rio Grande do Sul - Porto Alegre - RS - Brasil \\ Márcio Zamboni Neske \\ Universidade Estadual do Rio Grande do Sul/Campus Santana do Livramento - Santana do \\ Livramento - RS - Brasil \\ Marcos Flávio Silva Borba \\ Empresa Brasileira de Pesquisa Agropecuária/Pecuária Sul - Bagé - RS - Brasil \\ Paulo Dabdab Waquil \\ Universidade Federal do Rio Grande do Sul - Porto Alegre - RS - Brasil \\ Sergio Schneider \\ Universidade Federal do Rio Grande do Sul - Porto Alegre - RS - Brasil
}

\begin{abstract}
Resumo: O objetivo deste artigo é estudar um caso de relocalização alimentar e formação de cadeias curtas em dado local no sul do Rio Grande do Sul, por meio da venda de cordeiro por pecuaristas familiares do território Alto Camaquã. Para tanto, o caso analisado envolveu uma experiência em curso da construção de mercados da pecuária familiar, em específico de produção e comercialização da carne de cordeiro. O mercado da carne de cordeiro dos pecuaristas familiares recebe destaque por consistir em uma estratégia de revalorização da procedência de origem dos alimentos, destacando a construção de cadeias curtas nas formas estratégicas elaboradas entre produtores e consumidores para o estabelecimento de relações de comercialização dos produtores, construindo, desse modo, um processo de revalorização de um lugar e de um produto. Sendo assim, a venda local por pequenos produtores representa, entre tantos significados, um comprometimento de preservação da comunidade, da tradição, de conhecimento tácitos, entre outros valores não mercantis.

Palavras-chave: Cadeias curtas. Pecuária familiar. Relocalização.
\end{abstract}

\begin{abstract}
The aim of this paper is to study a case of food relocation and training of short chains in a given location in southern Rio Grande do Sul, through the sale of lamb ranchers for family livestock planning Alto Camaquã. Thus, the case analyzed involved an ongoing experience of building the family livestock farmers markets, in particular the production and marketing of lamb. The market lamb of family livestock farmers get highlighted because it consists of a strategy for upgrading the merits of origin for food, highlighting the construction of short chains in strategic ways compiled between producers and consumers to establish marketing relationships of producers, building thus a process of upgrading a place and a product. Thus, local sales by small producers is, among many meanings, a commitment to preserving the community, tradition, tacit knowledge, and other non-market values.
\end{abstract}

Keywords: Short chain. Family livestock farmers. Relocation.

\section{Introdução}


Em um mundo em que cresce a quantidade de alimentos produzidos e processados industrialmente, também aumenta a preocupação com sua origem e a forma como são elaborados. Críticos têm destacado que "rótulos" vêm sendo empregados por produtores de alimentos, varejistas e outros intervenientes na cadeia alimentar, visando a promover a diferenciação do produto em relação ao hegemônico, mas que, no entanto, nem sempre apresentam características de qualidade consideráveis (ILBERY et al., 2005; MARSDEN; MURDOCH, 2006).

Essas preocupações com a procedência dos alimentos e a confiança nos mesmos têm concentrado grande parte das atenções dos estudos rurais atuais. Diversas contribuições a reflexões nesse sentido são encontradas na literatura internacional, as quais têm realizado o esforço de explorar as relações entre os sistemas alternativos e convencionas, focando nas trajetórias do desenvolvimento e nos resultados das iniciativas de localização (FONTE, 2008; TREAGER, 2011).

Nesse contexto, o tema da relocalização espacial ou do lugar de procedência, assim como da identidade de quem produz, são duas das mais importantes características do processo de produção que vem sendo chamado de quality turn. $\mathrm{O}$ termo "quality turn" é uma expressão do papel cada vez mais ativo dos consumidores na política de construção de qualidade. Ele se apresenta como elemento propulsor de iniciativas contrárias às propostas homogeneizantes presente nos mercados (GOODMAN, DUPUIS, GOODMAN, 2012).

Segundo Goodman (2003), os debates em torno dos circuitos curtos de produção e abastecimento também representam uma resposta crítica aos grandes circuitos produtivos e às próprias crises e escândalos alimentares. Um dos aspectos centrais e decisivos na organização das cadeias curtas de suprimento refere-se à redefinição e mesmo à construção das relações com os mercados. Não há cadeia curta sem que ocorra o encurtamento ou estreitamento das distâncias e dos contatos entre produtores e consumidores. Logo, a análise de como se dá esse processo de construção de mercados passa a ser essencial para a afirmação e fortalecimento das cadeias curtas.

Uma das questões que emerge como interrogação dessa literatura internacional sobre a virada da produção alimentar para a qualidade e o local é saber em que medida essas tendências se verificam em países em desenvolvimento como o Brasil. Assim, o objetivo deste artigo é estudar um caso de relocalização alimentar e formação de cadeias curtas, por meio da venda de cordeiro por pecuaristas familiares, em um território da região sul do Rio Grande do Sul, o Alto Camaquã. O caso a ser relatado envolve uma experiência em curso que, adotando a estratégia de revalorização da procedência dos alimentos, pretende construir mercados de pecuária familiar de produção e comercialização da carne de cordeiro no território Alto Camaquã.

Este artigo se estrutura em três seções. A primeira, trata do debate em torno da emergência da localização como protagonista na ressignificação da produção agroalimentar que associa e valoriza aspectos como o enraizamento social do território, relações de confiança e, sobretudo, a formação de cadeias curtas na produção de alimentos. A segunda seção foca sua análise na discussão entre a localização da produção e a formação de cadeias curtas e sua aproximação com os mercados aninhados. Por fim, à luz da discussão realizada nas duas primeiras seções, a terceira seção apresenta a experiência da construção do mercado de cadeia curta da pecuária familiar para a comercialização da carne de cordeiro no território Alto Camaquã, no sul do Rio Grande do Sul. Por fim, são tecidas as considerações finais deste estudo.

\section{A relocalização agroalimentar e a revalorização da origem dos alimentos}


A emergência do debate em torno das redes alimentares alternativas ${ }^{1}$ (Alternative Food Networks - AFNs) ocorre inicialmente no ocidente, entre estudiosos europeus e norte-americanos, movidos principalmente por uma crítica sobre os sistemas intensivos de produção e processamento de alimentos. Goodman, Sorj e Wilkinson (1990) criticam o modelo hegemônico de produção, que, pelo seu modo de apropriacionismo e substitucionismo sobre o rural e sua produção, aumenta a distância entre produtor e consumidor. Além disso, o modelo hegemônico leva ao entendimento de que o conhecimento local do modo de produzir alimentos dos agricultores "não serve", passando a substituí-lo pelo conhecimento científico, visto então como válido e "correto".

Contudo, a homogeneização da produção e do consumo, discutida principalmente em literaturas internacionais, não ocorre da mesma maneira no Brasil, tendo trajetória distinta. Segundo Cruz (2012), a ruptura ocorrida na Europa e Estados Unidos não aconteceu aqui, pois, apesar de alguns agricultores aderirem às mudanças tecnológicas sugeridas pela indústria, bem como de consumidores alterarem sua maneira de consumir, não há um cessar ("fim") dos modos tradicionais locais de produção.

Nesse sentido, o livro Alternative food networks: knowledge, practice, and politics, de Goodman, DuPuis e Goodman (2012), centra-se no debate em torno de modelos de produção e distribuição de alimentos alternativos ou redes de alimentos alternativos, cumprindo um papel de contramovimento à tendência homogeneizante dos mercados agroalimentares. Segundo os autores, há um crescente movimento em busca de alimentos alternativos, incluindo os mercados locais, o que sugere que o modo de comer pode influenciar o tipo de comida produzida e seu processamento. Nessa obra, os autores procuram superar a ideia de que comida representa apenas as relações sociais e culturais, mas avançam ao afirmar que o alimento e as opções de consumo também representam críticas à globalização e à industrialização.

O termo "quality turn" ou "virada da qualidade" se apresenta como elemento propulsor de iniciativas contrárias às propostas homogeneizantes presentes no mercado, evocando para o debate noções de confiança e embeddedness (enraizamento) (GOODMAN, 2003). Em linhas gerais, a virada da qualidade traz ao debate elementos que atribuem qualidade aos alimentos, superando conformidades técnicas e levando em consideração elementos como cultura, tradição, modo de vida, vínculo com o natural entre outros (GOODMAN, DUPUIS, GOODMAN, 2012). O quality turn é também uma expressão do papel cada vez mais ativo dos consumidores na política de construção de qualidade, que "consiste na proliferação de redes alimentares alternativas, trazendo consigo preocupações com a segurança alimentar e a qualidade dos alimentos" (GOODMAN, DUPUIS, GOODMAN, 2012, p. 87).

De maneira geral, a literatura tem apontado e incorporado os consumidores como principais agentes na construção de projetos e demandas locais de alimentos (FONTE, 2008; TREGEAR, 2011). Em determinados locais, as economias alternativas têm esculpido posições relativamente independentes no sistema alimentar, evidenciando que esse movimento tem incentivado a construção de mercados justos com base na mudança dos consumidores que optam por uma alimentação alternativa, o que acaba por constituir um incentivo à produção local. De acordo com Treager (2011), as virtudes socioeconômicas dessas redes de alimentos alternativos têm sido exaltadas,

\footnotetext{
${ }^{1}$ Segundo Cruz (2012, p. 46), as redes alimentares alternativas estariam contribuindo para a promoção e valorização de alimentos considerados de qualidade, caracterizados por sabor e textura excepcionais, relações de confiança, centralidade do local e origem dos produtos, produção ecológica, justiça social, sistemas econômicos mais equitativos e, ainda, garantias em relação à segurança e valor nutricional.
} 
especialmente para a agricultura e para as comunidades rurais, mas também para os pequenos varejistas, consumidores, entre outros envolvidos nas economias regionais.

A partir dessa virada da qualidade, as cadeias alternativas de alimentos começam a ganhar evidência. Segundo Cruz (2012), um dos limites da emergência desse termo é a apropriação do "alternativo" por grandes multinacionais, que vislumbram nessa "virada" uma oportunidade de ampliar ganhos e expandir mercados. Por outro lado, oportuniza a abertura para o debate em torno dos sistemas agroalimentares locais, os quais têm o propósito de construir alternativas baseadas em alimentos locais, envolvendo ligações mais diretas entre agricultores e consumidores.

Dessa maneira, a emergência da relocalização como protagonista na ressignificação da produção agroalimentar que associa e valoriza aspectos como o enraizamento social do lugar, relações de confiança e, sobretudo, a formação de cadeias curtas na produção de alimentos tem ganhado espaço nos debates sobre a virada da qualidade. Nessa perspectiva, a qualidade do alimento encontra-se como elemento central para o debate em torno da produção e processamento, sendo necessário "reconhecer, valorizar e legitimar práticas e modos de produção, conhecimentos e relações de proximidade espontaneamente existentes" (CRUZ, 2012, p. 39). Treager (2011) afirma que os alimentos regionais oferecem oportunidades para relocalizar o controle econômico, valorizando a identidade cultural local integrada a recursos sócioecológicos e conhecimentos tácitos. Assim, as novas formas de heterogeneidade são especialmente importantes, na medida em que contribuem para a relocalização da agricultura (PLOEG, 2011).

Há atualmente um amplo debate em torno da relocalização da produção e consumo de alimentos, o qual tem tomado proporções a ponto de assumir as características de um novo paradigma, segundo alguns autores (FONTE, 2008; DUPUIS e GOODMAN, 2005; PLOEG et al., 2000; HINRICHS, 2003). O surgimento desses novos canais de comercialização, as redes de alimentos alternativos e o movimento do comércio justo emergem de uma resposta às contradições geradas pelo atual sistema alimentar industrial, considerado insustentável, e fazem frente às relações comerciais de exploração que orientam a expansão e reprodução desse sistema (GOODMAN, DUPUIS, GOODMAN, 2012). Desse modo, os sistemas agroalimentares locais têm o propósito de construir alternativas baseadas em alimentos do lugar, envolvendo ligações mais diretas entre agricultores e consumidores (GOODMAN e GOODMAN, 2007). Assim, valorizar a comida local também significa proteger e valorizar as especificidades daquele alimento e do seu modo de produção, reconhecendo e legitimando as contingências territoriais.

Para Fonte (2008), a valorização do local enquanto prática baseada no conhecimento das populações mobiliza as diversas formas de conhecimento incorporadas em atores rurais e não rurais. Conforme a autora, "relocalização de alimentos implica uma mobilização de conhecimentos" (FONTE, 2008, p. 211), no sentido de oposição ao homogêneo e em defesa do tradicional como um modo único e destoante do padronizado, preservando um modo de produzir e consumir de uma população. Para DuPuis e Goodman (2005, p. 361), o localismo torna-se uma contrahegemonia, uma oposição à tese da globalização, uma chamada à ação sob a alegação de que o "oponente ao poder global é o poder local". Em outras palavras, se a dominação é global, no local deve ser encontrada a liberdade. Assim, local, neste artigo, tem o mesmo sentido que para Fonte (2008, p. 202): refere-se a uma iniciativa de relocalização e às "condições especiais de produção de alimentos" e à "valorização de sua origem em mercados distantes". 
Convém salientar que o localismo representa um conjunto de valores e saberes locais livres de normas que resistem às "forças capitalistas contraditórias" (GOODMAN e GOODMAN, 2007, p. 27). Portanto, o localismo recebe destaque por direcionar atenção às relações sociais e às formas estratégicas elaboradas entre produtores e consumidores no estabelecimento das relações de comercialização dos produtos, construindo, desse modo, relações além das mercantis, de modo a fortalecer as interações sociais tanto entre produtores como entre estes e os consumidores. Sendo assim, a venda local por pequenos produtores representa um comprometimento de preservação da comunidade, da tradição, entre outros valores não mercantis.

Conforme Fonte (2008), há dois modelos de relocalização de alimentos em torno das redes locais de alimentos (local food networks), identificados pela autora com base em estudos de caso em dez países europeus. Um primeiro consiste na perspectiva da reconexão, que visa a reconstruir a relação entre produtores e consumidores. A discussão em torno desse modelo pressupõe que houve uma "ruptura", uma separação entre a produção de alimentos locais e os consumidores, sendo necessário "costurar" e reconectar o que foi rompido. Essa prática foi fortemente utilizada por multinacionais para inserir os produtos orgânicos em sua cadeia, apropriando-se de um "modo" de produção que passa a ser a demanda dos consumidores.

Conforme Ilbery et al.(2005), um mecanismo-chave para a reconexão, amplamente considerado, é o desenvolvimento e comercialização de produtos alimentares que são, de alguma forma, diferentes daqueles produzidos em massa e prontamente disponíveis nos principais pontos de venda, para que os consumidores possam aparentemente distingui-los dos demais. As diferenças podem ser na qualidade, na localização geográfica ou na forma de produção.

A segunda perspectiva é denominada de valorização da origem dos alimentos, que reposiciona a produção local de alimentos em relação aos seus valores, associado com práticas de produção de um território e com a tradição dessa população. Conforme Fonte $(2008$, p. 202), essa perspectiva está "enraizada em uma tradição pré-industrial que foi marginalizada, mas nunca se tornou completamente extinta". Ou seja, não houve uma ruptura ou o "fim" de um modo de produção em detrimento de outro. Esses alimentos permaneceram sendo produzidos com base em conhecimento tradicional mesmo frente ao avanço da industrialização, contudo, em escalas reduzidas e para públicos consumidores específicos. Da mesma forma, Cruz (2012) evidencia que, paralelamente ao avanço da globalização e da homogeneização do consumo alimentar, permanece coexistindo a produção local tradicional, sendo preservados os hábitos de consumo e produção locais.

Assim, neste artigo, adota-se a segunda perspectiva como orientadora, pois não se refere apenas à dimensão do espaço enquanto elemento de relocalização, mas também à dimensão de tempo, contemplando tradição e história, com base em processos contingenciais de um território. Por isso, ao se fazer referência a um local, isso também significa também que há uma proximidade. Assim, "proximidade refere-se a um lugar comum, mas também a uma história comum, um pertencimento comum que é solidificado em normas e regulamentos coletivos" (FONTE, 2008, p. 207). Trata-se, desse modo, de considerar a comida não apenas como um combustível e não só uma ocasião para a sociabilidade, "mas um patrimônio e, como tal, um forte elemento da identidade e da cultura local" (FONTE, 2008, p. 207).

Sendo assim, é a identidade territorial associada à geração dos alimentos que agrega valor a este. Portanto, a perspectiva da valorização da origem dos alimentos consiste em um amplo e variado conjunto de dimensões e significados que condizem 
com um movimento de reconhecimento e revalorização dos alimentos tradicionais, conforme afirma Cruz (2012, p. 273):

[...] a produção de alimentos tradicionais é resultado de combinações de características naturais, de ocupação da região, de conhecimentos e de técnicas particulares, compartilhados entre os grupos produtores e repassados de pais para filhos, entre os quais, além dos relacionados ao manejo da propriedade, estão também os conhecimentos, as técnicas e as práticas, elementos que, articulados conjuntamente, são capazes de originar, ao final do processo, produtos com características singulares.

De tal modo, o conjunto de características que pertencem apenas àquele lugar, e que, por inúmeras razões, não são reproduzidas com facilidade em outro ambiente, compõem o contexto do território Alto Camaquã, que será analisado mais à frente. Assim, a forma como a comida é comercializada pelos produtores locais é importante para a vida social e a identidade local da comunidade, bem como para a categoria social de pecuaristas familiares. De modo geral, o contexto dessas iniciativas agroalimentares é característico da forte presença de agricultores familiares marginalizados, que procuram nessas estratégias outras formas de assegurarem sua reprodução social e preservar sua tradição e seu modo de vida. De acordo com Fonte (2008, p. 218), a "valorização da origem dos alimentos implica pôr em movimento o rico estoque de conhecimento leigo tradicional que ainda persiste em muitas áreas rurais", como é o caso a ser analisado neste artigo.

Esse processo significa, portanto, que valorizar a comida local também significa proteger e valorizar as especificidades daquele alimento e do seu modo de produção, reconhecendo e legitimando as contingências territoriais. Desse modo, os sistemas agroalimentares locais têm o propósito de construir alternativas baseadas em alimentos do lugar, envolvendo ligações mais diretas entre agricultores e consumidores (GOODMAN e GOODMAN, 2007). Para Fonte (2008), uma das formas de incentivar e garantir os alimentos locais pode ser o registro do produto, certificando sua origem e modo de produção. Contudo, a autora esclarece que essa estratégia pode produzir efeitos negativos quando construída com base no conhecimento científico e por atores não locais, podendo vir a retirar a autenticidade de suas técnicas de produção. DuPuis e Goodman (2005) corroboram com a autora nesse aspecto. Para eles, corre-se o risco de criar um contexto favorável às elites locais e de construir territórios protegidos, gerando, consequentemente, desigualdades. Por isso, é fundamental repensar o local não como um movimento "romântico" para a sua emancipação, mas como uma ação coletiva, inclusiva e também reflexiva. Desse modo, a revitalização da origem da comida representa também recuperar o conhecimento tradicional, que representa a expressão do conhecimento local (FONTE, 2008).

Cabe ressaltar que a agricultura industrial global tem conseguido criar uma perda de singularidade na paisagem do lugar, e esse lugar tem papel importante na construção de sistemas alimentares alternativos (DUPUIS e GOODMAN, 2005). Conforme os autores, as redes de alimentos alternativos (cadeias curtas) é uma forma de resistir ao capitalismo por meio da ação racional. Sendo assim, esse processo de revalorização de alimentos em âmbito local pode acontecer por meio, por exemplo, de iniciativas como comercialização de alimentos de um local por intermédio de cadeias curtas, como a venda de um produto a um ponto específico de venda. Nesse sentido, a expansão da comercialização desses alimentos pode chegar aos consumidores de espaços urbanos através da criação de redes de alimentos (GOODMAN e GOODMAN, 2007; MARSDEN et al., 2000). Goodman (2003) salienta que o debate em torno dos circuitos curtos de produção e abastecimento também representa uma resposta crítica aos grandes 
circuitos produtivos e às próprias crises e escândalos alimentares. De tal modo, a construção de cadeias curtas representa uma maneira de assegurar a produção local e de inserir seus produtos em um mercado específico. A próxima seção desse artigo trata da construção social dos mercados de cadeias curtas.

\section{As cadeias curtas como alternativas de acesso aos mercados}

Para enfrentar as constantes tentativas de homogeneização da produção e consumo, e assegurar a integração dos pequenos produtores, é necessária a elaboração de alternativas personalizadas e sustentáveis, propondo uma nova visão que direcione a atenção para as relações sociais, econômicas e ecológicas autênticas entre todos os intervenientes no sistema alimentar (HENDRICKSON; HEFFERMAN, 2002; WILKINSON, 2008). Assim, no debate da relocalização, há um importante destaque em torno das cadeias curtas de abastecimento de alimentos (Short Food Supply Chain), como uma forma de valorizar o local e propor mudanças na maneira como são vistos os mercados e produtos locais. Diante da significativa relação com a noção de localidade, o geógrafo e sociólogo britânico Terry Marsden foi um dos estudiosos responsáveis por se dedicar, no final da década de 1990, a estudos nessa temática.

Marsden (2004) propõe o uso do termo "curto" para indicar a aproximação existente entre produção e consumo, tendo como propósito pensar os espaços alternativos fora dos espaços hegemônicos nos processos de produção, distribuição e consumo de alimentos. Nesse sentido, a valorização dos ativos locais de um território faz parte da proposição das cadeias curtas, as quais são consideradas como estratégias de revalorização da origem dos alimentos, estando diretamente interligada à discussão apresentada na seção anterior. O termo "curto" não se refere à distância física que o alimento percorre, mas, sim, à característica do produto ao chegar até o consumidor, preservando suas informações através de uma identificação própria ou da comunicação pessoal com quem o produz. Segundo Marsden et al. (2000, p. 425), "é isso o que permite ao consumidor a confiança de fazer conexões e associações com o lugar/espaço de produção, e, potencialmente, os valores das pessoas envolvidas e os métodos de produção utilizados". Ainda conforme os autores, por meio do desenvolvimento de novas definições de qualidade, associadas à localidade/território ou especialidade e natureza, novas redes associativas ou cadeias curtas de abastecimento podem ser construídas. Fica evidente que as cadeias curtas têm sido, cada vez mais, um importante instrumento para a relocalização e a revalorização dos alimentos a partir do lugar.

Uma das principais características das cadeias curtas é a capacidade dessas em "ressocializar" ou "reespacializar" um determinado alimento, permitindo ao consumidor associar juízos de valor com base no seu próprio conhecimento, experiência ou imaginário percebido (MARSDEN et al., 2000; RENTING; MARSDEN; BANKS, 2003; MARSDEN, 2004). Em outras palavras, é marcante nas cadeias curtas o envolvimento na construção de uma relação mais próxima entre produtor e consumidor, próxima não apenas no sentido físico, mas no de um conjunto de valores e significados que os interligam e os conectam. Assim, a construção de cadeias curtas de abastecimento está, também, fortemente relacionada com a definição de localização e no modo de produção dos alimentos, consistindo em uma fonte específica de alimentos de qualidade. Conforme Marsden (2004), as cadeias curtas de abastecimento procuram redefinir a relação produtor-consumidor, dando sinais claros quanto à origem do produto alimentar.

Sonnino e Marsden (2006a) defendem que circuitos curtos de abastecimento, ainda que inseridos dentro de circuitos convencionais, podem proporcionar novas 
relações entre produtores e consumidores, sendo, assim, capazes de promover a ressocialização ou reespacialização dos alimentos. Nesse enfoque, Cruz (2012, p. 47) afirma que "qualidade", "transparência" e "localidade" têm caracterizado os circuitos curtos, na medida em que relacionam qualidade e pequena produção, práticas tradicionais, paisagens, natureza e recursos locais.

Procurando entender como as cadeias de abastecimento alimentar são construídas, moldadas e reproduzidas ao longo do tempo e no espaço, é elaborado um conjunto de parâmetros teóricos e conceituais para auxiliar na compreensão dessas. De tal modo, Marsden et al. (2000, p. 425-426) identificam três principais tipos de cadeias curtas, sendo elas:

a) Face a face (Face-to-face): o consumidor adquiriu um produto direto do produtor/processador em uma base face a face. Autenticidade e confiança são mediadas pela interação pessoal. A Internet agora também apresenta oportunidades para uma variante do contato face a face por meio do comércio on-line e páginas da web.

b) Proximidade espacial (Spatial proximity): os produtos são produzidos e distribuídos na região específica (ou local) de produção, e os consumidores estão cientes da natureza "local" do produto no ponto de varejo.

c) Espacialmente estendido (Spatially extended): onde o valor e significado são carregados de informações sobre o local de produção e aqueles que produzem o alimento, sendo traduzido para os consumidores que estão fora da região e que podem não ter nenhuma experiência pessoal com a região de produção.

Em estudo realizado por Ferrari (2011) no Estado de Santa Catarina (Brasil), o autor analisa os três tipos de cadeias curtas apresentadas, que são desenvolvidas entre agricultores familiares, evidenciando a emergência de uma ampla variedade de novas cadeias alimentares. Segundo o autor, as cadeias curtas se caracterizam por enraizar práticas alimentares em relações ecossociais locais, criando novos espaços econômicos, conformando, por meio da produção e mercantilização de alimentos, uma relação de confiança entre produtores e consumidores. Com efeito, a emergência dessas cadeias curtas resulta de processos de proximidade, com significativa relação com a construção de redes por parte dos agricultores. A esse respeito, Marsden (1999, p. 507) argumenta que as cadeias curtas evidenciam as diferenças e particularidades das áreas rurais, bem como suas distintas capacidades em face aos mercados globais, criando, assim, "novas geografias rurais de valor".

De modo particular, pode ser observado como as buscas em torno de novas definições de qualidade podem ser capazes de redirecionar as ações de produtores locais, de tal forma que eles possam vir a desenvolver sua produção para um mercado específico. Embora possa ser uma maneira de promover o desenvolvimento rural, o desenvolvimento de novas relações sociais, estabelecidas nas cadeias curtas de abastecimento, também sugere um conjunto heterogêneo e diversificado de resultados de desenvolvimento ao invés de um modelo claramente generalizável espacialmente.

Outra abordagem que muito se aproxima a das cadeias curtas é a terminologia dos nested markets ou mercados aninhados ${ }^{2}$ (POLMAN et al., 2010; PLOEG, 2011; PLOEG, JINGZHONG, SCHNEIDER, 2012). Em suma, os mercados aninhados consistem de um conjunto específico de transações, envolvendo produtores e serviços específicos, entre fornecedores e compradores específicos, que obedecem a normas específicas e produzem benefícios específicos (PLOEG, 2011; PLOEG, JINGZHONG, SCHNEIDER, 2012). Essa especificidade socialmente construída define e reproduz o

\footnotetext{
2 Mercados aninhados podem ser vistos como uma forma de governança híbrida: um conceito desenvolvido na Nova Economia Institucional, que os vê como combinações específicas de incentivos de mercado e modalidades de coordenação (POLMANN et al., 2010, p. 296).
} 
mercado aninhado, que consiste de um conjunto de características que "circundam" esse mercado, formando um "ninho", por isso mercados "aninhados" (PLOEG, 2011). Conforme o autor, a diferença básica, contudo, é que os grandes mercados de produtos agrícolas e alimentares são, cada vez mais, governados por impérios alimentares, ao passo que os mercados emergentes estão inseridos em novas redes sociotécnicas que visam a proteger espaços específicos contra o regime imperial. Assim, os mercados aninhados significam limites, embora permeáveis, que delineiam um espaço em que as relações alternativas, tendências, identidades e as transações podem ser construídas (PLOEG, JINGZHONG, SCHNEIDER, 2010).

Entretanto, para Polman et al. (2010), o mercado aninhado vai além da definição de produtos "específicos". Para os autores esse mercado dispõe de um arranjo coordenado e conduzido por formas ativas de governança, provenientes dos parceiros e por meio de autoridades operacionais. Ou seja, inclui a participação ativa dos atores sociais envolvidos em fazer os mercados aninhados e organizarem os recursos comuns ${ }^{3}$. Conforme Polman et al. (2010), é necessário, portanto, um conjunto mais ou menos institucionalizado de regras para governar a gestão e o desenvolvimento dos recursos de uso comum. A exemplo disso, algumas das dimensões a serem compartilhadas entre produtores, enquanto possíveis recursos de uso comum, são a preservação da biodiversidade, a segurança da paisagem nativa, a reprodução de um modo de produção, a manutenção das características culturais da comunidade, a valorização do território como atração turística, entre tantos outros elementos comuns. Assegurar alguns desses recursos pode ser retribuído em reconhecimento e valorização dos produtos e das ações desenvolvidas naquele local, vindo a delinear os mercados aninhados, relocalizando a produção e reconectando produtor e consumidor, locais, ecossistemas e produtos, entre outros (POLMAN et al., 2010).

Portanto, os mercados aninhados auxiliam na compreensão dos processos de desenvolvimento rural como "respostas multifacetadas e de múltiplos níveis às falhas de mercado" associadas às dinâmicas dos mercados globais de commodities para a produção agrícola e de alimentos (PLOEG, 2011, p. 137). Segundo Ploeg (2011), enfrentar essa situação consiste em criar soluções locais para problemas globais, tratando de promover produtos altamente diferenciados, além de estilos de agricultura emergentes.

Nesse sentido, os comportamentos dos atores nos mercado de cadeia curta estão profundamente enraizados em redes de relações interpessoais, onde as relações sociais são fundamentais para a construção de mercados. De acordo com Starr (2010), as relações de respeito também fazem parte das transações econômicas, indo além de apenas uma troca de mercado, envolvendo uma satisfação pessoal para sua concretização. Para Abramovay (2004), os atores possuem suas representações mentais, a partir das quais se relacionam uns com os outros e, portanto, essas relações impactam na sua capacidade de realizar a comercialização. Desse modo, segundo o autor:

O estudo dos mercados como estruturas sociais enraíza os interesses dos indivíduos nas relações que mantêm uns com os outros e não supõe um maximizador abstrato, isolado, por um lado, e a economia, por outro, como resultado mecânico da interação social (ABRAMOVAY, 2004, p. 36).

\footnotetext{
${ }^{3} \mathrm{O}$ termo "recursos de uso comum" ou common pool resources, faz parte da teoria sobre os recursos comuns desenvolvida por Elinor Ostrom. Tais recursos de uso comum são utilizados por um grupo específico de indivíduos (usuários) que Ostrom denomina de "apropriadores", os quais compartilham "recursos-unidades". Assim, há um conjunto de regras que regulam a gestão e uso dos recursos compartilhados (OSTROM, 2010).
} 
Essa forma de abordagem dos mercados, também vem sendo utilizada nos estudos de formação de marcas de qualidade, no reconhecimento do local, na valorização da relação entre produtor e consumidor e nas regras que reconhecem os atributos de um produto que não seria identificado em um mercado aos moldes da economia clássica. Em suma, o desafio de uma cadeia curta é, também, manter os atores sociais unidos, motivando-os a cooperar, onde a organização dos grupos em redes significa também a continuidade da cadeia curta. As cadeias curtas, desse modo, são fruto de relações sociais e da formação de redes, associadas à confiança, ao local/território e ao enraizamento, onde a qualidade (quality turn) vem permear os processos alinhados com as cadeias alimentares curtas.

\section{0 cordeiro do Alto Camaquã/RS: um caso de revalorização alimentar e de construção de cadeia curta}

O propósito desta seção é apresentar um estudo de caso da construção social de um mercado de cadeia curta da carne de cordeiro do território Alto Camaquã enquanto uma estratégia de valorização do local. $O$ foco reside em identificar e analisar os pressupostos e as estratégias de interação empregadas pelas "mãos visíveis" dos atores sociais na construção do mercado.

O território Alto Camaquã está localizado na região fisiográfica denominada Serra do Sudeste do Rio Grande do Sul, fazendo parte do Bioma Pampa (Figura 1). Do ponto de vista político-administrativo, pertence à bacia hidrográfica do rio Camaquã, estando localizado no terço superior da mesma. Situam-se nos limites geográficos da bacia hidrográfica do Alto Camaquã partes das áreas dos municípios de Bagé, Caçapava do Sul, Encruzilhada do Sul, Lavras do Sul, Pinheiro Machado, Piratini e Santana da Boa Vista, o que compreende uma área de $8.172 \mathrm{~km}^{2}$ (FEPAM, 2009).

Figura 1. Mapa com localização geográfica do território Alto Camaquã

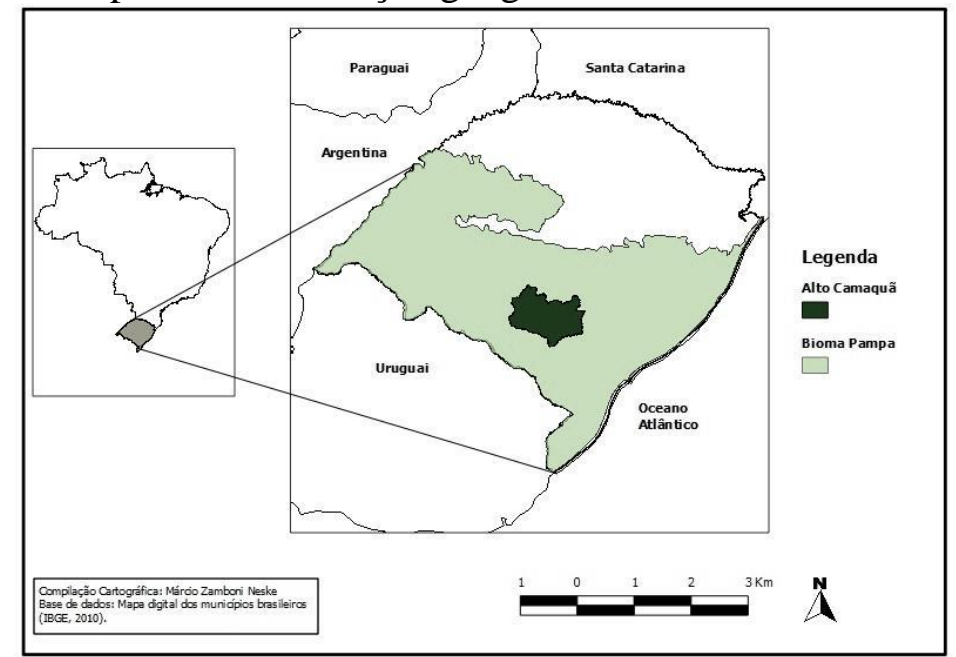

Nesse território, a pecuária de corte extensiva é a atividade produtiva predominante desde o período de colonização no século XVIII, exercida sobre áreas de campos naturais característicos do Bioma Pampa. Os pecuaristas familiares constituem a principal representação social e produtiva do Alto Camaquã, sendo que as propriedades rurais com até 50 hectares ocupam $60 \%$ do total de estabelecimentos e apenas $10 \%$ do total da área geográfica dos municípios, o que corresponde a $65 \%$ da população rural local (IBGE, 2006). 
No Alto Camaquã, assim como nas demais regiões do estado, a pecuária familiar é uma categoria social que foi forjada por meio de um processo coevolucionário estabelecido entre homem e natureza, o que tem definido, ao longo do tempo, espaços de convivência criados por relações contingenciais entre cultura e natureza. A consolidação da pecuária de corte enquanto atividade produtiva foi possível devido à existência de uma cobertura vegetal formada por extensas áreas de campos naturais nesse território. Decorrido um curso histórico de aproximadamente 200 anos desde o período de colonização até os dias atuais, os campos naturais representam a base da alimentação dos animais, e a conservação e manutenção desses campos tem sido possível devido à presença de uma cultura "ganadeira" localmente adaptada.

Portanto, ao se analisar os processos produtivos da pecuária familiar, deve-se considerar que os produtos comercializados (ex. carne, lã) são oriundos de formas de produção que envolvem relações particularizadas entre cultura, natureza e local. Porém, a trajetória do desenvolvimento do capitalismo agrário no Alto Camaquã criou mecanismos de mercados que geraram processos de exclusão e marginalização dos pecuaristas familiares, favorecendo os pecuaristas empresariais que incorporaram a "lógica" do mercado.

A pecuária de corte empresarial foi capaz de absorver em grande medida o progresso tecnológico engendrado pela modernização da agricultura, e, portanto, mobilizando recursos produtivos (insumos e serviços) via mercados. Esse modelo de produção tem alimentado a reestruturação da indústria de processamento nos tempos "modernos" (frigoríficos), a qual tem se constituído em verdadeiros impérios alimentares", exercendo um poder monopólico crescente sobre as relações que encadeiam a produção, o processamento e a distribuição dos alimentos. De acordo com Ploeg (2008), a industrialização das atividades agrícolas implica uma desconexão da agricultura com a natureza e com as localidades, pois o capital ecológico é substituído pelo capital financeiro e industrial.

Cada vez mais se verifica um processo de aprofundamento do controle dos canais de comercialização dos produtos da pecuária pelos frigoríficos, o que acaba gerando privilégios a poucos pecuaristas, e marginalizando um contingente enorme de tantos outros, sobretudo os familiares. Por outro lado, os processos de inovação e de modernização agrícola (via avanços tecnológicos) não tiveram grandes repercussões sobre as formas de produção e trabalho dos pecuaristas familiares. Esses pecuaristas usam tecnologias relativamente simples e, na sua maioria, rudimentares, em que o principal instrumento de trabalho é o "lombo do cavalo". Contudo, isso não significa que esses pecuaristas não façam uso do arsenal tecnológico disponível. Ressalta-se que o emprego de tecnologias externas se dá de forma fragmentada, mediante um processo de desconstrução/reconstrução, sempre limitado por seus conhecimentos parciais, baixa disponibilidade financeira e características ambientais. Desse modo, a reprodução social e econômica dos pecuaristas familiares é representativa de uma condição camponesa ${ }^{5}$, sendo mais dependente das "trocas" estabelecidas com a natureza do que os recursos mobilizados por meio dos mercados de insumos e serviços (NESKE; MIGUEL; BORBA, 2012; BORBA, 2002; BORBA, TRINDADE, 2009; WAQUIL et al., 2016).

Como forma de criar novos espaços e abordagens de entendimento e representação da pecuária familiar e do desenvolvimento para o Alto Camaquã, em

\footnotetext{
${ }^{4}$ Ploeg (2008) utiliza a expressão impérios alimentares para se referir às grande empresas que dominam e controlam os processos de produção, transformação e distribuição dos alimentos.

5 A condição camponesa consiste na luta por autonomia dos camponeses como uma forma de construção e reprodução de seu meio de vida rural em um contexto adverso, caracterizado por relações de dependência, marginalização e privação (PLOEG, 2008).
} 
2008, a Empresa Brasileira de Pesquisa Agropecuária - Embrapa, localizada no Município de Bagé, desenvolve um projeto de desenvolvimento denominado de Projeto Alto Camaquã. Trata-se de um projeto concebido a partir de uma abordagem territorial para pensar e promover estratégias de desenvolvimento no território. Segundo Borba e Trindade (2009), o Projeto Alto Camaquã trata de ações de intervenção que visam a "redescobrir" e "re-valorizar" o local como portador de experiências e elementos socioeconômicos, culturais e ambientais próprios capazes de gerar e suportar estratégias endógenas de desenvolvimento rural (BORBA, TRINDADE, 2009). Fundamentalmente, o projeto tem renunciando à visão estigmatizada de atraso e improdutividade do desenvolvimento do Alto Camaquã e dos sistemas produtivos familiares, procurando criar condições para ressignificar os signos da narrativa moderna de outros modos, por meio da valorização do local.

O projeto Alto Camaquã interliga uma rede de multiatores, na qual, além da Embrapa, são parceiros a Emater ${ }^{6}$, associações de produtores, representações sindicais (Federação dos Trabalhadores na Agricultura - Fetag, Sindicatos dos Trabalhadores Rurais - STR), governo municipal e estadual (por intermédio da Secretária de Desenvolvimento Rural - SDR) e algumas universidades. Os processos de ação do projeto têm buscado criar estratégias que possam promover a imagem do território Alto Camaquã e vincular essa imagem e seus atributos com produtos e serviços do território.

Multiprocessos envolvem as ações do projeto, sendo os resultados deste representados por experiências na organização social. Como resultados, foram criados: a Associação para o Desenvolvimento Sustentável do Alto Camaquã - ADAC em 2009, que congrega e representa o conjunto das associações dos pecuaristas familiares, e tem como missão promover e viabilizar estratégias de desenvolvimento junto aos agentes sociais, econômicos e políticos do Alto Camaquã; a Rede de Produtores e Empreendedores do Alto Camaquã - REAC, que, desde sua criação em 2011, promove durante o ano encontros das associações de produtores e empreendedores do Alto Camaquã; a feira de produtos do Alto Camaquã, realizada anualmente desde 2010; a criação do Fórum do Alto Camaquã, que representa o principal espaço de governança local, pois se trata de um espaço coletivo de discussão entre diferentes atores locais para o planejamento de ações do desenvolvimento local; e novos arranjos organizacionais de pesquisa/extensão, o que resultou na criação de um programa de pesquisa participativa juntamente com os pecuaristas familiares. A condução das pesquisas participativas tem envolvido principalmente a participação da Embrapa, que desempenha importante papel na rede de atores, pois estabelece no interior do projeto Alto Camaquã as principais ligações que orientam as ações de desenvolvimento do projeto.

As ações do Projeto Alto Camaquã atuam na forma de rede juntamente com as associações de produtores. Atualmente 20 associações comunitárias de pecuaristas familiares são filiadas à $\mathrm{ADAC}$, o que representa em torno de 280 famílias de pecuaristas. As primeiras iniciativas para acessar mercados com os produtos do Alto Camaquã iniciaram em 2011. Durante esse ano, foram organizados encontros da Rede Alto Camaquã - ReAC, contando com a participação da ADAC, associações de produtores filiadas à $\mathrm{ADAC}$, sindicatos dos trabalhadores rurais, Embrapa, Emater, prefeituras municipais e SDR para definição das primeiras tratativas e estratégias de comercialização de produtos e serviços do território, além da criação de uma marca coletiva dos produtos e serviços que visa à certificação participativa e à venda coletiva de produtos.

\footnotetext{
${ }^{6}$ Associação Sulina de Crédito e Assistência Rural - Ascar/RS, entidade oficial de extensão rural no Rio Grande do Sul. Opera no Alto Camaquã com escritórios municipais e dois escritórios regionais com sede nos municípios de Bagé e Pelotas.
} 
No ano de 2012, novos encontros da ReAC possibilitaram avançar na construção de acesso aos mercados. Em maio e junho desse ano, duas novas reuniões definiram os produtos para iniciar a comercialização e as estratégias de uso da marca territorial coletiva $^{7}$. Cabe destacar que a definição de cada produto como potencial para comercialização envolve uma decisão partilhada entre pecuaristas das distintas associações e demais atores de agências já mencionadas. O universo de produtos identificados como próprios do território foram organizados em cinco "linhas" de produtos, sendo elas: arte rural, carnes, produtos alimentícios elaborados, produtos primários e turismo. Entre algumas das características definidas na escolha dos produtos estão aspectos relacionados ao "saber-fazer", produtos "ecológicos" (sem uso de insumos externos) e adaptados ao local, paisagem e recursos naturais preservados.

As primeiras comercializações dos produtos do território ocorreram na feira de produtos do Alto Camaquã, que ocorre anualmente no mês de julho. No entanto, a carne de cordeiro foi o produto que obteve um processo mais acelerado e fortalecido de comercialização. Isso porque a produção ovina é praticada em $100 \%$ das propriedades familiares que participam do Projeto Alto Camaquã, o que ampliaria a possibilidade de inserção nos mercados de boa parte dos pecuaristas.

Definido o cordeiro como "carro-chefe" do processo de comercialização, foram estabelecidos, na reunião da ReAC, em junho de 2012, os critérios e regulamentos do "cordeiro típico" do Alto Camaquã: os cordeiros devem ser 1) produzidos no território (produção própria dos membros da ADAC); 2) de raças diversas, machos (castrados) ou fêmeas com no máximo 14 meses; 3) criados em campo nativo, aceitando-se suplementação para acabamento com fontes de concentrado não transgênicos produzidas no território Alto Camaquã; 4) comercializados com peso entre $30 \mathrm{~kg}$ e 40 $\mathrm{kg}$.

Nesse sentido, em março de 2013, a ReAC realizou uma nova reunião para definir estratégias de comercialização do cordeiro do Alto Camaquã com dois novos atores. Nessa ocasião, foi fechado acordo comercial com um pequeno frigorífico local, com sede em Encruzilhada do Sul, que passou a ser responsável pelo abate e comercialização dos cordeiros.

Assim, os diferentes atores definiram estratégias de industrialização e comercialização da carne de cordeiro com a marca coletiva do território Alto Camaquã. A carne de cordeiro vem sendo comercializada no mercado local do território, e a inserção da pecuária familiar nesse mercado está associada a um mercado construído socialmente que teve a participação efetiva dos pecuaristas. Mas, além disso, a construção desse mercado somente foi possível, entre outras coisas, porque se trata de um mercado que se mostra "adequado" à realidade das formas de produção e trabalho desses pecuaristas. Trata-se, portanto, de um mercado aninhado, mas não simplesmente por ser um mercado emergente, mas por possuir fronteiras permeáveis para a entrada de novos atores, o que redefine constantemente estruturas de trabalho e relações sociais pautadas por objetivos comuns.

O mercado da carne de cordeiro do território do Alto Camaquã representa uma estratégia às falhas do mercado, pois a estrutura predominante no território não incorpora os produtos da pecuária familiar. A carne de cordeiro é carregada de um conjunto de atributos e valores relacionados ao local, atualmente vendida em um ponto específico, em que nem todos os consumidores conhecem o local/território de produção, mas, de alguma forma, reconhecem o modo de produção e as características que diferenciam o alimento.

\footnotetext{
7 Atualmente a marca se encontra em fase de registro junto ao Instituto Nacional de Propriedade Industrial - INPI.
} 
Dessa maneira, a cadeia curta de abastecimento funciona da seguinte maneira. A cada semana uma associação é responsável pela comercialização dos animais. Os animais são reunidos, pesados e levados diretamente para o frigorífico com sede no Município de Encruzilhada do Sul. O transporte dos animais até o frigorífico é subsidiado pelas prefeituras dos municípios. O preço praticado foi estipulado de maneira que o produtor possa receber um valor maior que o preço do mercado "convencional". Até o momento, o parceiro comercial responsável pela venda da carne de cordeiro é do Município de Encruzilhada no Sul. Porém, atualmente está sendo visualizada a possibilidade de acesso a novos mercados para a pecuária familiar, estando em curso um processo de organização para o acesso aos mercados institucionais do Programa de Aquisição de Alimentos - PAA e Programa Nacional de Alimentação Escolar - PNAE (Figura 2).

A parte inicial desta seção tratou dos aspectos relacionados aos dispositivos que originaram a formação da cadeia curta do cordeiro no Alto Camaquã, bem como a forma como essa cadeia está estruturada. No entanto, é importante destacar quais os aspectos que tornam a carne de cordeiro e o mercado de cadeia curta diferentes dos demais. A própria emergência de novos mercados para a sociologia econômica pode ser explicada por diversos elementos, dentre os quais fatores relacionais, políticos, culturais, tradicionais etc., intervindo significativamente sobre a formação dos mercados e sobre fatores econômicos (STEINER, 2006). 
Figura 2. Cadeia curta de comercialização do cordeiro Alto Camaquã

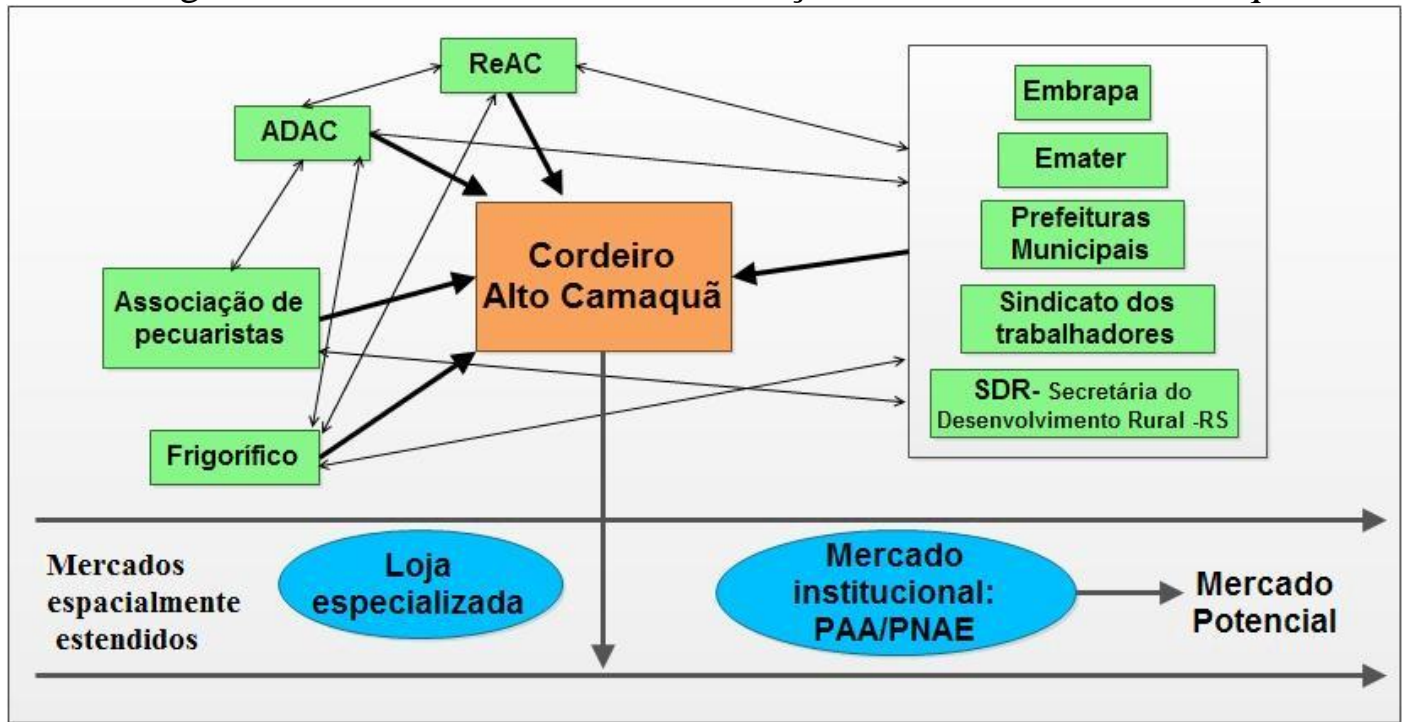

Fonte: Elaborado pelos autores.

Os resultados encontrados na análise do mercado do cordeiro do Alto Camaquã corroboram com os resultados de estudo realizado por Brunori et al. (2008) acerca da cadeia de carne local da região de Mugello, na Toscana (Itália). Os pecuaristas de Mugello desenvolvem a atividade em pequenas propriedades. De modo geral, a pecuária de corte é a principal atividade. Os animais, criados de maneira extensiva, alimentam-se de pastagens naturais. Com significativa dificuldade de comercializar seu produto, esses produtores criaram uma cooperativa como resposta à fraqueza de seus produtos no mercado local. Apesar da carne local não possuir um rótulo específico de qualidade, a cooperativa foi capaz de criar confiança e reputação para a carne produzida por esses pecuaristas entre os consumidores locais de Mugello, assegurando uma rede de comercialização e promovendo a emergência da revalorização de um produto local, com garantia de qualidade e produção.

Em estudo realizado por Sonino e Marsden (2006) em três redes locais de alimentos alternativos no Sudoeste da Inglaterra (creme de leite, rede de carne e queijo), os autores constatam que o modo de produção das famílias investigadas está baseado na antiga tradição e na herança das gerações anteriores, estando claramente enraizada no tempo e no espaço, com ênfase na qualidade do produto. Os autores constatam que a relocalização e revalorização de alimentos nessa região ocorrem devido a uma "retroinovação", que consiste em um processo de inovação, combinando elementos de um passado tradicional com a atual circunstância em que se encontra a agricultura (SONNINO; MARSDEN, 2006b). Essa terminologia também implica traduzir e comunicar criticamente alguns elementos das práticas produtivas aos varejistas e consumidores por meio da rotulagem, do registro de marca e do estabelecimento de critérios de qualidade, os quais são baseados no local em que os animais são criados, na identidade de seus produtos e nas técnicas de processamento. Assim, essa rede de alimentos alternativos estimula economias locais ao se inserir nas relações pessoais e de reciprocidade e confiança.

Os resultados de ambos os estudos permitem constatar que o caso do cordeiro do Alto Camaquã representa uma estratégia que se aproxima de outros contextos, até mesmo internacionais, e que, acima de tudo, consiste em um processo de revalorização da produção local, apresentando um produto de qualidade particular, associado a um 
lugar, a um modo de vida e de produção, característico de uma região com uma história preservada há mais de dois séculos.

Nesse aspecto, a noção de qualidade ganha relevância na construção do mercado do cordeiro do Alto Camaquã. Ou seja, a qualidade está relacionada às qualidades presentes em ativos culturais, sociais, econômicos, produtivos, institucionais e ambientais presentes no local, os quais estão sendo mobilizados para a diferenciação dos produtos e dos processos de comercialização. Desse modo, se a produção de cordeiro ocorre em um local único, de paisagem e características naturais e culturais únicas, é um produto diferenciado por conta desses aspectos. Essa noção de "qualidades" está enraizada no local, pois foi construída e vem sendo compartilhada entre diferentes atores engajados na construção do mercado do cordeiro.

O campo nativo e o modo de criação dos animais (saber-fazer dos pecuaristas) representam importantes elementos no localismo da carne de cordeiro. Nesse sentido, os cordeiros produzidos sobre essas áreas de campo nativo possuem diferenciações em seu sabor, se comparado a animais que têm em seu sistema de criação uma alimentação pré-elaborada pela indústria.

Os atores sociais passaram a definir uma imagem dos produtos do território como "naturalmente único", pois são produtos integrados a processos produtivos em que a cultura "ganadeira" desenvolveu formas específicas de relação com a natureza, mantendo preservados, ao longo do tempo, a paisagem e os recursos naturais. Essa característica representa um dos atributos da carne de cordeiro do território do Alto Camaquã e constitui uma estratégia de valorização dos recursos locais e naturais, e, portanto, um pressuposto à valorização da origem do alimento. Assim, com base nesses elementos, a rede de atores e processos que compõem o Projeto Alto Camaquã vem trabalhando em uma proposta de localismo do desenvolvimento, pautado pela valorização dos ativos do território.

Assim, a história do Projeto Alto Camaquã é marcada por processos de aprendizagem e de fortalecimento do processo de organização social, pois se trata de uma experiência de desenvolvimento que tem suscitado regimes de enunciação até então inexistentes no Alto Camaquã. Vale ressaltar que no curso do Projeto Alto Camaquã, constantemente novos atores se aproximaram, da mesma forma que outros se afastaram, e assim vem ocorrendo sem interrupção. A esse respeito, Granovetter (2009) enfatiza a importância das redes na análise do comportamento econômico, pois, segundo o autor, a estrutura e o comportamento dos mercados dependem das relações pessoais e das redes entre as empresas e dentro delas.

\section{Considerações finais}

O mercado da carne de cordeiro do Alto Camaquã representa um processo contestatório diante dos modelos de produção de alimentos hegemônicos. De modo particular, pode-se observar a busca em torno de novas definições de qualidade associadas ao local, compreendida como uma estratégia de relocalização a partir de um contexto específico, gerado por uma rede social ampla e variada. A mobilização e valorização de formas locais de conhecimento são o cerne da cadeia curta em andamento por meio do Projeto Alto Camaquã.

Assim, a construção social desse mercado de cadeia curta tem permitido a construção de processos coletivos de comercialização, no qual pecuaristas e demais atores sociais locais apoiam-se mutuamente na logística, no transporte, na produção e na comercialização, promovendo assim a organização social do mercado. A partir dessa organização de atores sociais de distintos âmbitos, tem-se ampliado as atenções para a 
própria categoria de pecuaristas familiares, os quais permaneceram (ou permanecem), por muito tempo, marginalizados aos esforços de desenvolvimento rural. A maneira como estes se relacionam com os recursos naturais e como manejam os animais em conformidade com o ambiente permite atribuir um valor intrínseco ao produto, riqueza gerada em nível local, fruto dos conhecimentos tácitos dos produtores, bem como das características do alimento.

O desenvolvimento de cadeias curtas de abastecimento e de mercados aninhados apresenta desafios para as instituições e órgãos encarregados de apoiar atividades econômicas e sociais de áreas rurais. O desafio das políticas públicas envolve ações holísticas na rede, incluindo a reinserção do rural e de um modo de produção territorial como formas de reconstruir a valorização do lugar. Além disso, o caso analisado demonstra que a relocalização de alimentos é uma exceção à tendência de homogeneização da agricultura e de suas técnicas agroalimentares, o que aponta que o conhecimento local e o enraizamento das formas de produção são asseguradas quando mercados como o analisado conseguem manter-se.

Os resultados observáveis dessa experiência envolvendo a construção social de mercados não dizem respeito apenas à possibilidade de acessar novos mercados para a pecuária familiar. Essa, certamente, é uma questão importante a ser considerada, já que a venda de cordeiro tem redundado em uma melhor valorização e remuneração dos pecuaristas familiares. No entanto, o que cabe ressaltar é que os resultados dessa experiência, que estão colocados para os atores envolvidos, dizem respeito ao desvelamento de uma categoria social marginalizada - considerada "rude" - e de um território estigmatizado como pobre e atrasado pela imensa maioria das instituições de ensino e desenvolvimento e pelo poder público.

Desconstruir a noção de pobreza enraizada no imaginário geográfico e social foi, e continua sendo, uma premissa "consciente" que tem orientado a base das ações de desenvolvimento do Projeto Alto Camaquã, o que evidencia que o desenvolvimento rural não é uma mera aplicação de ações e políticas modernizantes na tentativa de corrigir problemas que são criados como "anomalias". Os desafios colocados ao Alto Camaquã estão em expandir e enriquecer essa experiência de desenvolvimento, conservando o conjunto de ativos locais para convertê-los em potencial para o desenho de alternativas à lógica homogeneizadora do desenvolvimento. Nesse sentido, o caso analisado do mercado de cordeiro, evidenciando a relocalização da produção e abastecimento de alimentos, demonstra que a construção social de mercados é uma estratégia importante de práticas enriquecidas de alteridade. 


\section{REFERÊNCIAS}

ABRAMOVAY, R. Entre deus e o diabo: mercados e interação humana nas ciências sociais. Tempo Social. Revista de Sociologia da USP, SP, USP, v. 16, n. 2, p. 35-64, 2004.

BECKERT, J. The social order of markets. Theory and Society, v. 38, n. 3, p. 245-269, 2009.

BORBA, M.F.S. La marginalidad como potencial para la construccion de "outro" desarrollo: El caso de Santana da Boa Vista, Rio Grande do Sul, Brasil. 2002. 362 f. Tesis (Doctorado em Sociologia, Agroecologia e Desenvolvimento Sustentável). Instituto de Sociología y Estudios Campesinos, Universidad de Córdoba, España, 2002.

BORBA, M.F.S; TRINDADE, J. P. P. Desafios para conservação e a valorização da pecuária sustentável. In: PILLAR, V. P. de; MÜLlER, S. C.; CASTILHOS, Z. M. S. de; JACQUES, A. V. Á. (Org.). Campos Sulinos - conservação e uso sustentável da biodiversidade. Brasília: Ministério do Meio Ambiente, p. 391-403, 2009.

BRUNORI, G. et al. Looking for alternatives: the construction of the organic beef chain in Mugello, Tuscany. International Journal of Agricultural Resources, Governance and Ecology. v. 7, n. 1/2, p. 126-143, 2008.

CRUZ, F.T. Produtores, consumidores e valorização de produtos tradicionais: um estudo sobre qualidade de alimentos a partir do caso do queijo serrano dos Campos de Cima da Serra - RS. 2012. 292f. Tese (Doutorado em Desenvolvimento Rural) Universidade Federal do Rio Grande do Sul, Programa de Pós-Graduação em Desenvolvimento Rural, Porto Alegre, 2012.

DUPUIS, M. E., GOODMAN, D. Should We Go "Home" to Eat?: toward a reflexive politics of localism. Journal of Rural Studies, v. 21, n. 3, p. 359-371, 2005.

FERRARI, D. Cadeias agroalimentares curtas: a construção social de mercados de qualidade pelos agricultores familiares em Santa Catarina. 2011. 347f. Tese (Doutorado em Desenvolvimento Rural). Universidade Federal do Rio Grande do Sul, Programa de Pós-Graduação em Desenvolvimento Rural, Porto Alegre, 2011.

FONTE, M. Knowledge, food and place: a way of producing, a way of knowing. Sociologia Ruralis, v. 48, n. 3, p. 200-222, 2008.

GOODMAN, D. The quality 'turn' and alternative food practices: reflections and agenda. Journal of Rural Studies, v. 19, n. 1, p. 1-7, 2003.

GOODMAN, D.; GOODMAN, M. Localism, livelihoods and the 'post-organic': changing perspectives on alternative food networks in the United States. In: MAYE, D; HOLLOWAY, L.; KNEAFSEY, M. (Eds.). Alternative Food Geographies: representation and practice. $1^{\mathrm{a}}$ Ed. Oxford, UK, 2007. p. 23-38.

GOODMAN, D. DUPUIS, M. E., GOODMAN, M. K. Alternative food networks: knowledge, practice, and politics. London and New York, O Routlege, 2012. 
GOODMAN, D.; SORJ, B.; WILKINSON, J. Da lavoura às biotecnologias: agricultura e indústria no sistema internacional. Rio de Janeiro: Campus, 1990.

GRANOVETTER, M. Ação econômica e estrutura social: o problema da imersão. In: MARTES, A. C. B. (Org.). Redes e sociologia econômica. São Carlos: EdUFSCar, p. 31-68, 2009.

HENDRICKSON, M. K.; HEFFERNAN, W. D. Opening spaces through relocalization: locating potential resistance in the weaknesses of the global food system. Sociologia Ruralis, v. 42, n. 4, p. 347-369, 2002.

HINRICHS, C. C. The practice and politics of food system localization. Journal of Rural Studies, v. 19, n. 1, p. 33-45, 2003.

ILBERY, B. et al. Product, process and place an examination of food marketing and labelling schemes in Europe and North America. European Urbanand Regional Studies, v.12, n. 2, p.116-132, 2005.

INSTITUTO BRASILEIRO DE GEOGRAFIA E ESTATÍSTICA. Pecuária 2006. Rio de Janeiro: $2006 . \quad$ Disponível em: <http://www.sidra.ibge.gov.br/bda/tabela/listabl.asp?z=t\&o=24\&i=P\&c=1244>.

Acesso em: 23 nov. 2011.

MARSDEN, T. Rural Futures: The Consumption Countryside and its Regulation. Sociologia Ruralis, Oxford, v. 39, n. 4, p. 501-520, 1999.

MARSDEN, T. et al. Food Supply Chain Approaches: Exploring their Role in Rural Development. Sociologia Ruralis, Oxford, v. 40, n. 4, p. 424-438, 2000.

MARSDEN, T. Theorising food quality: some key issues in understanding its competitive production and regulation. In: HARVEY, M.; MCMEEKIN, A.; WARDE, A. (Ed.). Qualities of food. New York: Palgrave, p. 129-155, 2004.

MARSDEN, T.; MURDUCH, J. Between the local and the global: confronting complexity in the contemporany agri-food sector. Research in Rural Sociology and Development. Cariff-UK: Elsevier, v. 12, 2006.

NESKE, M. Z.; MIGUEL, L. A.; BORBA, M. F. S. Capital ecológico e a construção de autonomia na produção familiar: o caso da pecuária familiar do Rio Grande do Sul. Cadernos de Ciência \& Tecnologia, v. 29, p. 291-317, 2012.

OSTROM, E. Beyond Markets and States: Polycentric Governance of Complex Economic Systems. American Economic Review, Pittsburgh, v. 100, n. 3, p.1-33, 2010. 
PLOEG, J. D. van der. Camponeses e Impérios Alimentares. Lutas por autonomia e sustentabilidade na era da globalização. Porto Alegre: Ed. da UFRGS, 2008.

PLOEG, J. D. van der. et al. Rural Development: from practices and policies towards theory. Sociologia Ruralis, Oxford, v. 40, n. 4, p. 391-407, 2000.

PLOEG, J. D. van der. Trajetórias do desenvolvimento rural: pesquisa comparativa internacional. Sociologias, Porto Alegre, v.7, n. 27, p. 114-140, 2011.

PLOEG, J. D. van der.; JINGZHONG, Y.; SCHNEIDER, S. Rural development reconsidered: building on comparative perspectives from China, Brazil and the European Union. Rivista di Economia Agraria, n. 2, p. 163-190, 2010.

PLOEG, J. D. van der.; JINGZHONG, Y.; SCHNEIDER, S. Rural development through the construction of new, nested, markets: comparative perspectives from China, Brazil and the E.U. Journal of Peasant Studies, v. 39, n. 1, p. 37-41, 2012.

POLMAN, N. et al., Nested markets with common pool resources in multifunctional agriculture. Rivista di Economia Agraria, n. 2, p. 295-318, 2010.

RENTING, H.; MARSDEN, T.; BANKS, J. Understanding alternative food networks: exploring the role of short food supply chains in rural development. Environment and Planning A, v. 35, N. 3, p. 393-411, 2003.

SONNINO, R.; MARSDEN, T. Beyond the divide: rethinking relationships between alternative and conventional food networks in Europe. Journal of Economic Geography, v. 6 , n. 2, p. 181-199, 2006a.

SONNINO, R.; MARSDEN, T. Alternative food networks in the South West of England: towards a new agrarian eco-economy? In: MARSDEN, T.; MURDUCH, J. Between the local and the global: confronting complexity in the contemporany agrifood sector. Research in Rural Sociology and Development. Cariff-UK: Elsevier, v. 12, p. 299-322, 2006b.

STARR, A. Local Food: A Social Movement? Cultural Studies Critical Methodologies, Califórnia, v. 10, n. 6, p. 479-490, 2010.

STEINER, P. A sociologia econômica. Tradução de Maria Helena Trylinski, São Paulo: Editora Atlas, 2006.

TREGEAR, A. Progressing knowledge in alternative and local food networks: critical reflections and a research agenda. Journal of Rural Studies, v. 27, n. 4, p. 419-430, 2011.

WAQUIL, P. et al. Pecuária familiar no Rio Grande do Sul: história, diversidade social e dinâmicas de desenvolvimento. 1. ed. Porto Alegre: Editora da UFRGS, 2016. (Série Estudos Rurais)

WILKINSON, J. Mercados, redes e valores. Porto Alegre: Ed. UFRGS, Série Estudos Rurais, 2008. 
Submetido em 27/01/2015

Aprovado em 26/07/2016

\section{Sobre os autores}

Alessandra Matte

Zootecnista, Mestre e Doutoranda em Desenvolvimento Rural, pelo Programa de Pós-Graduação em Desenvolvimento Rural - PGDR, da Universidade Federal do Rio Grande do Sul - UFRGS.

E-mail: alessandramatte@yahoo.com.br

\section{Márcio Zamboni Neske}

Doutor em Desenvolvimento Rural - PGDR/UFRGS. Professor da Universidade Estadual do Rio Grande do Sul - UERGS, Campus Santana do Livramento/RS.

E-mail: marcio.neske@gmail.com

\section{Marcos Flávio Silva Borba}

Doutor em Sociologia, Agroecologia e Desenvolvimento Sustentável pela Universidade de Córdoba, Espanha. Pesquisador da EMBRAPA Pecuária Sul/RS.

E-mail: marcos.Borba@embrapa.br

\section{Paulo Dabdab Waquil}

Doutor em Economia Agrícola (University of Wisconsin, EUA). Professor dos Programas de PósGraduação em Desenvolvimento Rural (PGDR) e Agronegócios - CEPAN da Universidade Federal do Rio Grande do Sul - UFRGS.

E-mail:waquil@ufrgs.br

\section{Sergio Schneider}

Doutor em Sociologia. Professor dos Programas de Pós-Graduação em Desenvolvimento Rural - PGDR e Sociologia - PPGS da Universidade Federal do Rio Grande do Sul - UFRGS.

E-mail: schneide@ufrgs.br 